\title{
The flexibility of the transverse arch of the forefoot on the forefoot loading in the flat feet deformity
}

\author{
Shintarou Kudo ${ }^{1 *}$, Yasuhiko Hatanaka ${ }^{1,2}$ \\ From 4th Congress of the International Foot and Ankle Biomechanics (i-FAB) Community \\ Busan, Korea. 8-11 April 2014
}

\section{Background}

For the flat foot deformity, the custom made foot orthosis supported medial longitudinal arch using the navicular pad. And we experienced many cases that addition the metatarsal pad which supported transverse arch of the forefoot was more effective treatments. However, the flexibility of the transverse arch in the flat foot deformity was unclear. The aim of this study was to clarify the flexibility of the transverse arch of the forefoot in the flat foot deformity on the forefoot loading condition.

\section{Methods}

The sixty-one feet of fifty-two normal volunteers (32 males and 19 females, $22.0 \pm 3.8$ years old) were participated in this study. They were categorized normal feet group and flat feet group by their foot posture and medical history around the foot. The ten spherical $4 \mathrm{~mm}$ diameter skin markers were mounted over the each metatarsal heads and bases. Measurement foot stance forward and body weight lorded on the forefoot as well as possible with whole plantar surface in contacted with the floor. Foot motion was recorded using four Hi-definition digital video cameras with $60 \mathrm{~Hz}$. The ground reaction force and plantar foot distributions were recorded using the force plate (Anima.co, Japan) and the Win-pod (Medicaputures s.a.s. France) with $180 \mathrm{~Hz}$, respectively. The each marker was manually digitized using the Flame Dias4. The calibration flame was used $64 \mathrm{~mm}^{3}$ acryl cubes. The distance from the first to the fifth metatarsal head and base were calculated as forefoot and mid foot width (FFW and MFW), respectively. The transverse arch height of both the metatarsal head and base (TAHH and TAHB) was defined as the distance from the second metatarsal head and base to the floor divided by FFW and MFW, respectively. The difference FFW and TAHH, MFW, TAHB between rearfoot and forefoot loading were measured as Diff- FFW and Diff-TAHH, Diff-MFW, Diff-TAHB. The four parameters were assessed among the two groups using Mann-Whitney test.

\section{Results}

The Diff-FFW and the Diff-TAHH had significant difference between two groups. And the Diff-MFW and the Diff-TAHB didn't have significant difference (Table 1).

\section{Conclusion}

It was needed for physical therapy of the foot to understand kinematics of the forefoot in the dynamic condition. The forefoot flexibility with the flat foot deformity was greater than that with the normal feet. It might be better to insert the metatarsal pad which aimed to increase the rigidity of the forefoot.

Table 1 The difference four parameters between standing and forefoot loading [median (25\%-75\%)].

\begin{tabular}{cccc}
\hline & Normal feet & Flat feet & p-values \\
\hline Diff-FFW & $1.52 \%(1.17-2.11)$ & $2.08 \%(1.78-3.07)$ & $\mathrm{p}<0.001$ \\
\hline Diff-TAHH & $1.79 \%(1.28-2.45)$ & $2.78 \%(2.15-3.63)$ & $\mathrm{p}<0.001$ \\
\hline Diff-MFW & $1.31 \%(0.94-1.66)$ & $1.17 \%(0.94-1.66)$ & $\mathrm{p}=0.21$ \\
\hline Diff-TAHB & $3.20 \%(2.33-4.68)$ & $3.18 \%(2.68-4.23)$ & $\mathrm{p}=0.46$ \\
\hline
\end{tabular}

\footnotetext{
* Correspondence: shintarou.iimt@gmail.com

'Graduate school of medical science, Suzuka University of Medical Science, Suzuka, Mie, 510-0293, Japan

Full list of author information is available at the end of the article
} 


\section{Authors' details}

'Graduate school of medical science, Suzuka University of Medical Science,

Suzuka, Mie, 510-0293, Japan. ${ }^{2}$ Department of Physiotherapy, Suzuka

University of Medical Science, Suzuka, Mie, 510-0293, Japan.

Published: 8 April 2014

doi:10.1186/1757-1146-7-S1-A48

Cite this article as: Kudo and Hatanaka: The flexibility of the transverse arch of the forefoot on the forefoot loading in the flat feet deformity. Journal of Foot and Ankle Research 2014 7(Suppl 1):A48.

Submit your next manuscript to BioMed Central and take full advantage of:

- Convenient online submission

- Thorough peer review

- No space constraints or color figure charges

- Immediate publication on acceptance

- Inclusion in PubMed, CAS, Scopus and Google Scholar

- Research which is freely available for redistribution

Submit your manuscript at www.biomedcentral.com/submit
() BioMed Central 